\section{RELACIO $N$ ES}

Relaciones. Estudios de historia y sociedad ISSN: 0185-3929

relacion@colmich.edu.mx

El Colegio de Michoacán, A.C

México

Herrera González, Patricio

La sociedad salarial mexicana y su compleja integración social en un contexto revolucionario

Relaciones. Estudios de historia y sociedad, vol. XXXI, núm. 124, 2010, pp. 125-140

El Colegio de Michoacán, A.C

Zamora, México

Disponible en: http://www.redalyc.org/articulo.oa?id=13718469005

- Cómo citar el artículo

Número completo

- Más información del artículo

Página de la revista en redalyc.org

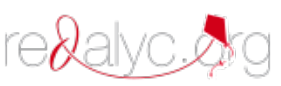

Sistema de Información Científica

Red de Revistas Científicas de América Latina, el Caribe, España y Portugal

Proyecto académico sin fines de lucro, desarrollado bajo la iniciativa de acceso abierto 


\title{
LA SOCIEDAD SALARIAL MEXICANA Y SU COMPLEJA INTEGRACIÓN SOCIAL EN UN CONTEXTO REVOLUCIONARIO
}

\author{
Canta, canta, obrero productor, \\ que cantando las fatigas \\ pasanse mucho mejor. \\ Ocho horas de trabajo, \\ ocho horas de instrucción, \\ ocho de horas de descanso, \\ esa es nuestra aspiración, ¡jh! ${ }^{1}$
}

1 documento que presento exhibe a una escala reducida los complejos problemas que significaron para México, de principios del siglo $\mathrm{XX}$, reconocer a los trabajadores como sujetos de derecho y partícipes de la modernidad capitalista. Zamora, una localidad pequeña, enclavada en las tierras fértiles del occidente de México, con una incipiente urbanización y fuertemente vinculada a un mercado muy activo de consumidores procedentes de las haciendas y rancheríos próximos, contaba con alrededor de 19 mil habitantes al despuntar el siglo xx. Su actividad económica, asociada a la comercialización de productos agrícolas, manufacturas artesanales e industria de alimentos, hizo que más temprano que tarde las organizaciones laborales, la clase política y el propio gobierno municipal, que estaba ad portas de transitar, como el conjunto del país, un accidentado camino hacia cambios estructurales, pudo descubrir la envergadura de los escenarios del desempleo, la falta de protección laboral, la arbitrariedad en los montos y pagos de salarios, las prácticas laborales de antiguo

1 "Los trabajadores", La defensa obrera, Valparaíso, Chile, 16 de mayo de 1914. Citado en Juan Carlos Yáñez Andrade, La intervención social en Chile, 1907-1932, Santiago, RiL editores y PEDCH, 2008, 226. 
régimen, la imprevisión social, el poder de las asociaciones patronales y la ausencia de una política social para asalariados y no asalariados.

En este sentido, el documento aporta, desde una escala microscópica, el complejo escenario de la organización social del trabajo en México, resultado del esfuerzo de múltiples actores sociales y políticos, que no estuvo exento de rupturas, negociaciones e indiferencias - por parte de autoridades locales y federales, inclusive en la propia burguesía revolucionaria- y que la sola existencia de un discurso de transformación y revolución sociopolítica no fue condición para solucionar los problemas estructurales de la clase trabajadora y de paso asegurar la cohesión social.

La historia del derecho social y laboral ha sido la disciplina que ha dado pistas para comprender el debate jurídico, pero disociado de los contextos históricos de larga duración. En este sentido, creemos, que se debe avanzar hacia un registro histórico que, junto al aparato jurídico, pero también social y económico, dé cuenta de las ramificaciones de este debate en el espacio público, donde la clase política, los obreros "ilustrados" e intelectuales expresaron en voces polifónicas la necesidad de un consenso político, social y económico para implementar las transformaciones en materia laboral y social necesarias para el país y la causa revolucionaria.

EL DESCUBRIMIENTO DE LA SOCIEDAD SALARIAL:

ENTRE EL RECONOCIMIENTO Y LA INTEGRACIÓN

El desarrollo del derecho mexicano del trabajo está íntimamente vinculado con el movimiento revolucionario que se inició en 1910. Los propósitos de la política laboral y las metas a que aspiraba se encuentran entre las ideas motrices de la Revolución. Fue ésta la que comenzó a llevar a la práctica las primeras aplicaciones de medidas legislativas en relación con el trabajo, y el triunfo definitivo del movimiento revolucionario abrió en México la era del derecho del trabajo.

Las condiciones de los trabajadores, obreros y campesinos, desde mediados del siglo XIX fueron "inhumanas", de explotación y amparadas por la ley. Las rutinas de trabajo exhiben una brutal forma de "plusvalía" -absoluta, relativa y circulante-a la que eran sometidos los trabajadores durante el porfiriato: 
Jamás se pensó en un código de trabajo, protector de la clase obrera. Las fábricas, por medio de trabajos impropios o excesivos, agotantes y peligrosos, podían volver estéril a la obrera y hacerla abortar, tuberculizar y destruir niños, mutilar o matar obreros, asfixiar y distribuir pestes en talleres malsanos, focos de infección, temibles por falta de aire puro, de luz, de aseo, de sequedad. El personal debía trabajar catorce y diez y seis horas por día; sufrir descuentos de sus jornales por multas [...] Nunca el general Díaz tuvo la menor preocupación por la clase obrera; jamás tuvo movimientos altruistas por los miserables; su legislación fue muda para aliviar a las pobres víctimas de una injusticia magna, calculada por los más serenos e intransigentes capitalistas, habituados a hacer monedas, abatiendo vidas de infelices obreros. ${ }^{2}$

Sin embargo, la propia Constitución de 1857 dejaba una alternativa abierta al proletariado. El espíritu abiertamente liberal de tal legislación garantizaba, a través de su artículo $9^{\circ}$, la libertad de asociación de los trabajadores. A lo largo del siglo XIX y hasta el cambio de esta legislación en 1917, este derecho fue cobrando realidad en el millar de organizaciones surgidas en el seno del proletariado mexicano: La Sociedad de Mineros de Zacatecas, La Asociación Potosina de Obreros, La Suprema Hermandad de Aguascalientes, la Alianza de la Clase Trabajadora, el Gran Círculo de Obreros, la Gran Confederación de Trabajadores, el Círculo de Obreros de Jalapa, la Suprema Orden de Empleados del Ferrocarril, fueron sólo algunas de las organizaciones de trabajadores; que bajo la modalidad del mutualismo y cooperativas procuraron desarrollar una política asistencialista, dado el nulo apoyo, en la promoción y defensa de sus derechos sociolaborales por parte del Estado.

Así mismo, proliferaron una serie de publicaciones de estas organizaciones obreras, El Socialista, El Hijo del Trabajo, La Comuna, entre otras, que tenían como principal misión formar una conciencia de clase y denunciar la "dominación social capitalista".

Hacia finales de la dictadura porfirista, la economía nacional estaba sumergida en una profunda crisis industrial, agrícola y comercial:

${ }^{2}$ Alfredo Breceda, México Revolucionario, Tomo I, Madrid, Tipografía Artística, 1920, 38-39. 
el esquema de crecimiento con estabilidad política había generado fuerzas capitalistas crecientes cuya plena expansión no permitía ya el sistema. Además, en el exterior estaban gestándose profundos cambios que habrían de afectar la continuidad de la pauta de crecimiento, lo que escapaba a la posibilidad de manipulación del núcleo dirigente. La manera de crecimiento que consistía en una abierta orientación hacia el exterior- matizada por cierto grado de proteccionismo en algunas actividades de interés interno había producido los máximos beneficios inmediatos pero también había condicionado la imposibilidad de alterar la orientación del crecimiento mediante la diversificación de la producción y de mercados externos. ${ }^{3}$

Este proceso de deterioro económico-social convertirá al proletariado, urbano y rural, en el eje de las agitaciones del movimiento obrero. El ciclo de estas movilizaciones, muchas de ellas muy violentas, se incrementaron sistemáticamente desde 1880. Las huelgas de Cananea en 1906, de Río Blanco en 1907 y la de ferrocarrileros en 1908, marcan el pináculo de la lucha obrera por el reconocimiento de sus derechos laborales y políticos. A esas alturas, los obreros "ilustrados" habían descubierto un lenguaje común de organización política y conciencia de clase, lo que permitió generar sus mecanismos de defensa ante la indiferencia del Estado y la explotación capitalista.

El conjunto de demandas presentadas por los obreros y que fueron la razón de las huelgas durante el porfiriato tuvieron como causa: la disminución del salario y la infructuosa petición de su incremento; que no se pagaba a los trabajadores en metálico o se hacía con vales; los malos tratos que en algunos casos llegaban a los golpes; el aumento de la jornada de trabajo; el despido de operarios; la lucha contra el trabajo dominical y el nocturno; la limitación de las entradas y salidas de la fábricas; el sistema de multas y castigos empleados. ${ }^{4}$

Es importante señalar que en las huelgas de Cananea, de Río Blanco y de ferrocarrileros, el Partido Liberal Mexicano actuó como órgano po-

${ }^{3}$ Sergio de la Peña, La formación del capitalismo en México, México, Siglo xxI Editores, $1975,227$.

${ }^{4}$ Moisés González Navarro, Las huelgas textiles en el porfiriato, México, Ed. José González Jr., 1970, 15-16. 
lítico directivo. Entre sus miembros más destacados se encontraban Juan Sarabia, Librado Rivera, Ricardo Flores Magón y Antonio Díaz Soto y Gama. En un principio esta organización partidista luchó por el cabal cumplimiento de la Constitución de 1857. Este planteamiento original evolucionó hacia el enfrentamiento a la dictadura porfirista y después en contra del orden social capitalista existente, fundando el anarcosindicalismo, liderado por los hermanos Flores Magón.

Para 1904, habían aparecido en el panorama jurídico nacional algunas normas que se apartaban de las clásicas, con las que el derecho civil pretendía conducir las relaciones laborales. Las iniciativas fueron de José Vicente de Villada, gobernador del Estado de México en 1904; y la de Bernardo Reyes, gobernador del Estado de Nuevo León en 1906; el contenido de esos ordenamientos sólo se referían a accidentes profesionales y a enfermedades de los trabajadores. Aunque eran avances en la ampliación del debate legislativo, la ausencia de una proyección hacia una verdadera reforma social tan profunda como la exigían los obreros, cuyas reivindicaciones y conquistas habían sido postergadas durante largos años, no permite catalogar esas incompletas leyes como una nueva era en las condiciones laborales y de vida de la clase proletaria. El aporte de estas iniciativas fue constituir un:

repertorio moderno de la acción colectiva [...] Sólo cuando a través de la letra impresa, las asociaciones y la construcción del Estado se difundieron formas flexibles, adaptables e indirectas de acción colectiva, se desarrollaron movimientos sociales nacionales. Éstos aglutinaron a amplias coaliciones de seguidores en torno a exigencias genéricas, haciendo buen uso de las oportunidades políticas creadas por la expansión del Estado Nacional. [Por tanto] el Estado no sólo sirvió de blanco de las reclamaciones colectivas, sino, cada vez más, de punto de apoyo de las exigencias planteadas a otros. ${ }^{5}$

El 5 de octubre de 1910, Francisco I. Madero expidió el Plan de San Luis, desconociendo al régimen porfirista y convocando al pueblo al restablecimiento de la Constitución y a la introducción del principio de no reelección: en el punto cuarto hizo referencia al problema obrero al decir

${ }^{5}$ Sidney Tarrow, El poder en movimiento, Madrid, Alianza Editorial, 1997, 26. 
en la base vI: "mejorar la condición moral, material e intelectual del obrero, creando escuelas y talleres, procurando la expedición de leyes sobre pensiones e indemnizaciones por accidentes de trabajo". ${ }^{6}$

El triunfo de la revolución maderista abrió las puertas para una intensa actividad obrera. Los trabajadores empezaron a organizar sindicatos de resistencia, los cuales introdujeron nuevos lenguajes de autodefensa por la conquista de sus derechos laborales e implementaron estrategias políticas que buscaban engrosar las filas de los militantes a su causa. La fundación de la Casa del Obrero Mundial en 1912 fue un impulso que les brindó la oportunidad para intensificar las labores sindicales.

El presidente Madero, en su propósito de atender debidamente los problemas obreros, creó, el 15 de diciembre de 1911, el Departamento del Trabajo, dependiente de la Secretaría de Fomento, Colonización e Industria. Este fue el primer organismo gubernamental encargado de los asuntos del proletariado industrial en la historia del país.

El otro paso importante en materia laboral durante la presidencia de Madero fue, al concluir el año 1911, ordenar a Abraham González y al licenciado Federico Garza, secretario y subsecretario de Gobernación respectivamente, que formulasen las bases generales para la reelaboración de la legislación obrera vigente en el periodo anterior. Las principales indicaciones abordadas, por ambos burócratas, trataron el apartado de la seguridad social, específicamente lo referente a las condiciones de seguridad y salubridad para los obreros en los talleres y fábricas, así como seguros por accidentes de trabajo.

Tanto las funciones del Departamento de Trabajo -con actividades muy limitadas en materia de estadísticas, bolsa de trabajo e investigación de la situación obrera- y la iniciativa de transformar la legislación vigente en materia laboral se quedó en un verdadero proyecto. Madero defraudó los anhelos de los obreros y campesinos, lo que motivó una mayor organización de lo trabajadores para exigir una transformación de base a sus miserias y abusos laborales.

El 15 de julio de 1914, la dictadura del "usurpador" general Huerta fue derrotada por las fuerzas carrancistas, cediendo el triunfo a la Revo-

${ }^{6}$ Manuel González Ramírez, Fuentes para la historia de la Revolución Mexicana, Tomo I, Planes Políticos, México, Fondo de Cultura Económica, 1954, 33. 
lución constitucionalista. Como un acto demostrativo de los nuevos tiempos de reformas "estructurales" se iniciaron importantes propuestas legislativas en relación con el derecho del trabajo.

LA INTERVENCIÓN SOCIAL REVOLUCIONARIA: LA ORGANIZACIÓN SOCIAL

DE LOS TRABAJADORES DESDE ARRIBA

En Aguascalientes, el 8 de agosto de 1914, se legisló para reducir la jornada de trabajo a nueve horas; se impuso el descanso semanal y se prohibió cualquier reducción en los salarios.

El 15 de septiembre, de ese mismo año, se decretó en San Luis Potosí sobre los salarios mínimos. Unos días más tarde en el estado de Tabasco se redujo a ocho horas la jornada de trabajo, se fijó un salario mínimo y se eliminaron las deudas de los campesinos. Pero el mayor peso cualitativo de toda esta corriente legislativa en materia laboral se elaboró en los estados de Jalisco y Veracruz. En el primero de ellos, Manuel Diéguez (líder obrero en los tiempos de Cananea) expidió un decreto, el 2 de septiembre de 1914, sobre jornada de trabajo, descanso semanal obligatorio y vacaciones; y el 7 de octubre, Manuel Aguirre Berlanga publicó la que puede ser considerada la primera ley del trabajo de la Revolución constitucionalista. En ella se trataron casi todas las necesidades obreras menos el contrato colectivo: jornada de trabajo de nueve horas, prohibición del trabajo de los menores de nueve años, salarios mínimos en el campo y en la ciudad, protección del salario, reglamentación del trabajo, sobre el riesgo profesional, accidentes del trabajo y creación de las Juntas de Conciliación y Arbitraje.

En el estado de Veracruz, el 4 de octubre de 1914 se impuso el descanso semanal y el 19 del mismo mes Cándido Aguilar expidió la Ley del trabajo del Estado. Se trató de una ley muy avanzada para la época, pues buscó una protección laboral y social de los obreros: jornada máxima de nueve horas, descanso semanal, salario mínimo, accidentes del trabajo, riesgo profesional, escuelas primarias sostenidas por los "patrones", inspección del trabajo, tribunales obreros. Un año después, el 6 de octubre de 1915 se promulgó la ley, elaborada por Agustín Millán, de asociaciones profesionales que otorgó reconocimiento legal al movimiento obrero y estimulaba la organización de sindicatos en el estado. 
El gobernador del estado de Yucatán, el general Salvador Alvarado, se propuso reformar el orden social y económico en su totalidad, a cuyo efecto expidió las leyes que se conocen con el nombre de Las cinco hermanas: agraria, de hacienda, del catastro, del municipio libre y del trabajo, un intento de reformar toda la vida social. La Ley del trabajo, expedida el 6 de enero de 1915, buscó otorgar un reconocimiento a la "república de los trabajadores". Reglamentó las instituciones colectivas: asociaciones, contratos colectivos y huelgas. Comprendió también las bases del derecho individual del trabajo: jornada máxima, descanso semanal, salario mínimo y defensa de las compensaciones. Así como también indemnización por accidentes, seguros de vida y contra accidentes, y medidas higiénicas en el trabajo. Se encuentran también las normas para el trabajo de las mujeres y de los menores de edad. La ley creó las Juntas de Conciliación y el Tribunal de Arbitraje, encargados del conocimiento y decisión de todos los conflictos de trabajo individual y colectivo, jurídico y económico.

Resulta también interesante la legislación del estado de Coahuila de 1916, obra del gobernador Gustavo Espinosa Mireles: un decreto del mes de septiembre creó dentro de los departamentos gubernamentales una sección de trabajo; y en el mes siguiente publicó, el mismo gobernador, una ley inspirada en el Proyecto Zubarán y en la Ley de Bernardo Reyes sobre accidentes de trabajo; su interés principal radica en las disposiciones que ordenaban la participación obrera en las utilidades, tal vez la primera norma legislativa sobre este importantísimo tema. ${ }^{7}$

A pesar de toda esta legislación, durante el gobierno de Carranza poco se hizo por poner en práctica la Constitución de 1917, y en materia de trabajo no fue la excepción ya que no se efectuó un esfuerzo trascendente por reglamentar el artículo 123, que fue la expresión de la legislación elaborada entre 1904-1916.

El Primer Jefe deseaba una presidencia fuerte para dirigir el cambio. Por tanto, fue enemigo de las huelgas y organizaciones laborales autónomas, su proyecto político para México consistía en "un país de grandes capitalistas y de hombres educados que pudieran dirigirlo al pro-

${ }^{7}$ Moisés Poblete, El movimiento obrero latinoamericano, México, Fondo de Cultura Económica, 1946, 214-239; Susie Porter, Mujeres y trabajo en la Ciudad de México, México, El Colegio de Michoacán, 2008, 313. 
greso, dejando la responsabilidad al Estado de proteger la soberanía de México, de moralizar a la sociedad y de promover la redistribución de la riqueza por medios institucionales". 8

Por temor, a un escenario político faccional, Carranza retiró su apoyo a los trabajadores y evidenció una actitud hostil hacia las organizaciones obreras.

El texto original del citado artículo 123 constitucional otorgó a las legislaturas de los estados la facultad de dictar las leyes reglamentarias del mismo. En tal virtud, a partir de 1917, cada una de las entidades federativas promulgó leyes del trabajo, las cuales se ajustaron a los preceptos constitucionales. En pocos años, floreció la legislación del trabajo, que para el caso del estado de Michoacán se tradujo en que su primera ley estatal del trabajo se decretó el 1 de septiembre de 1921, lo que en parte explica que los trabajadores - expresados en el documento- quedaran sometidos a los arbitrios de sus patrones o en el mejor de los casos negociaran condiciones laborales que no daban cabal cumplimiento al artículo 123 de la carta constitucional.

Sin embargo, multitud de problemas creados por la aplicación de las leyes locales determinaron la necesidad de una codificación unitaria de la legislación laboral. El primer paso fue la creación de la Junta Federal de Conciliación y Arbitraje por decreto del ejecutivo federal, el 22 de septiembre de 1927. Dos años más tarde, fueron reformados los artículos 73 y 123 de la Constitución, para dar facultad exclusiva al Congreso de la Unión para legislar en materia de trabajo.

Los años que estuvieron vigentes las leyes del trabajo de los estados fueron fecundos, porque la aplicación de dicho cuerpo de leyes tuvo un efecto benéfico al empezar a reformar costumbres y prácticas en el mundo del trabajo, haciendo realidad muchos de los propósitos del legislador. Durante esta época, la Suprema Corte de Justicia fijó la interpretación de los preceptos constitucionales relativos al trabajo y, de manera principal, la función de las Juntas de Conciliación y Arbitraje, que quedaron investidas de poder jurisdiccional como verdaderos tribunales para resolver las controversias entre el capital y el trabajo.

${ }^{8}$ Luis Barrón, Carranza. El último reformista porfiriano, México, Tusquets Editores, 2009, 237. 
Las reformas constitucionales aludidas permitieron la federalización de las leyes del trabajo. El antecedente inmediato de la Ley en vigor fue un proyecto elaborado el año 1929, conocido con el nombre de Proyecto Portes Gil. Este proyecto no llegó a convertirse en ley.

El año 1931, la Secretaría de Industria, Comercio y Trabajo elaboró otro nuevo que fue enviado por el presidente Pascual Ortiz Rubio al Congreso de la Unión. Esta iniciativa fue aprobada, con algunas modificaciones, y se convirtió en Ley Federal del Trabajo expedida en agosto de 1931.

La aplicación de la Ley Federal del Trabajo tuvo en teoría la finalidad de elevar el nivel de vida de la clase trabajadora, pero su aspecto más trascendente consistió en que, siendo este Código un conjunto de derechos mínimos de la clase trabajadora, proporcionó una relativa mejoría en las condiciones de vida del asalariado, a través del ejercicio del derecho de huelga y las contrataciones colectivas.

El régimen de seguridad social venía a complementar, de forma indispensable, el derecho del trabajo que se había establecido en la Constitución de 1917. Se trataba de la culminación de una demanda justa, digna y merecida para la clase trabajadora de México.

Fue a iniciátiva del presidente Lázaro Cárdenas que se llevaron a cabo una serie de cambios institucionales que configuraron no sólo el moderno sistema político, sino que también La institucionalización definitiva de la "República de los "Trabajadores", como resultado de una trayectoria histórica, y no de respuestas mecánicas al desafío planteado por la estructura industrial moderna. Los distintos sectores consensuaron e integraron a visiones comunes la tarea de los órganos del Estado hacia el cumplimiento de las leyes laborales y la creación de un sistema de seguridad social. No es casual entonces que el modesto Departamento del Trabajo, creado en 1911, se haya transformado finalmente en la Secretaría del Trabajo y Previsión Social en 1940, en palabras de García Téllez, México estaba a la altura de las circunstancias:

La previsión social no es sino una manifestación de la suprema acción tutelar del Estado en las actividades productivas, como anticipación y complemento del impulso de las masas trabajadoras hacia su bienestar. Esta función del Estado ha rebasado los límites de la jurisdicción doméstica para 
convertirse en programas internacionales que proclaman el indispensable reconocimiento de un código de derechos fundamentales de los trabajadores inspirados en la justicia social, como necesario para lograr la paz y el progreso de las naciones. ${ }^{9}$

La modesta solicitud laboral de trabajadores zamoranos del comercio de hacer respetar el descanso dominical y las horas de trabajo, garantizados por la Constitución de 1917, nos proporciona evidencias para identificar las complejidades que demandó la organización social del trabajo en México en un contexto revolucionario. Pero también nos lleva a plantearnos la paradoja de cómo en otras realidades del continente, como en Argentina y Chile, ${ }^{10}$ se avanzaba en una codificación laboral equivalente a lo realizado en México, pero sin los fuegos cruzados que habían costado un millar de vidas y enormes fracturas sociales.

\section{BIBLIOGRAFÍA}

BARrón, Luis, Carranza. El último reformista porfiriano, México, Tusquets Editores, 2009.

BreCEDA, Alfredo, México Revolucionario, Tomo I, Madrid, Tipografía Artística, 1920.

De la PeÑa, Sergio, La formación del capitalismo en México, México, Siglo XXI Editores, México, 1975.

GARCíA TÉLLEz, Ignacio, "La iniciativa de Ley del Seguro Social Obligatorio", en El seguro social en México, IMSS, México, 1943.

_, "La previsión social y las clases trabajadoras", en Revista Trabajo y Previsión Social, núm. 42, México, Secretaría del Trabajo y Previsión Social, 1941.

GoNZÁLEZ NAVARRO, Moisés, "La propiedad y el trabajo ene el porfiriato",

\footnotetext{
${ }^{9}$ Ignacio García Téllez, "La previsión social y las clases trabajadoras", en Revista Trabajo y Previsión Social, núm. 42, Secretaría del Trabajo y Previsión Social, México, 1941, 6.

${ }^{10}$ Eduardo Zimmermann, Los liberales reformistas. La cuestión social en la Argentina, 1890-1916, Buenos Aires, Editorial Sudamericana, Universidad de San Andrés, 1995; Juan Carlos Yáñez Andrade, La intervención social, op. cit.
} 
en Daniel Cosío Villegas, Historia Moderna de México, El Porfiriato, La vida social, México, Editorial Hermes, 1973.

, Las huelgas textiles en el porfiriato, México, Ed. José González Jr., 1970.

GonzÁlez Ramírez, Manuel, Fuentes para la historia de la Revolución Mexicana, Tomo I, Planes Politicos, México, Fondo de Cultura Económica, 1954.

Hoвsваwм, Eric, Historia del siglo xx, Barcelona, Crítica, 1998.

Oficina Internacional del Trabajo, Legislación social de América Latina. Tomo I y II, Ginebra, OIT, 1928.

Poвlete, Moisés, El movimiento obrero latinoamericano, México, Fondo de Cultura Económica, 1946.

Porter, Susie, Mujeres y trabajo en la Ciudad de México, México, El Colegio de Michoacán, 2008.

SÁnChEZ VARGAS, Gustavo, "Orígenes y evolución de la seguridad social en México", en Cuadernos de Sociología, México, unam, 1963.

TARROW, Sidney, El poder en movimiento, Madrid, Alianza Editorial, 1997.

Tena, Felipe, Leyes fundamentales de México (1808-1857), México, Ed. Porrúa, 1958.

YáÑez ANDRADE, Juan Carlos, La intervención social en Chile, 1907-1932, Santiago, RiL editores y PEDCH, 2008

ZeRTUCHE, Fernando (Coordinador), Historia del Instituto Mexicano del Seguro Social, México, IMSS, 1980.

ZIMMERMANN, Eduardo, Los liberales reformistas. La cuestión social en la Argentina, 1890-1916, Buenos Aires, Editorial Sudamericana, Universidad de San Andrés, 1995.

Patricio Herrera González

El Colegio de Michoacán.

herrerapb@colmich.edu.mx 
DOCUMENTO

OCURSO PRESENTADO POR VARIOS EMPLEADOS DE CAJONES DE ROPA DE ESTA CIUDAD, PIDIENDO EL DESCANSO DE LOS DÍAS FESTIVOS, ASÍ COMO LA REGLAMENTACIÓN DE LAS HORAS DEL TRABAJO, ZAMORA, 14 DE ENERODE $1919 .{ }^{11}$

Ciudadano Presidente Municipal.

LOSSUSCRITOS, empleados del Comercio de esta Ciudad, ante Usted con todo respeto exponemos: QUE según lo dispuesto por las fracciones I. y IV. del artículo 123 de la Constitución Política de los Estados Unidos Mexicanos, la jornada máxima de trabajo tendrá una duración de ocho horas y por cada seis días de trabajo deberá disfrutarse un día de descanso, cuando menos, debiendo sujetarse á las horas fijadas todo contrato de trabajo, entre los que la expresada disposición constitucional enumera á los empleados, en cuya categoría nos contamos los suscritos. Hasta ahora la duración de la jornada máxima ha sido superior á ocho horas diarias y no hemos disfrutado del descanso á que nos dá derecho el precepto invocado, por lo que, siendo esa Presidencia Municipal la encargada de velar por el exacto cumplimiento de las disposiciónes constituciónales, venimos á solicitar respetuosamente que se fíjen por la misma las horas de trabajo en todos los establecimientos mercantiles, sin que exedan de las fijadas y que se nos señale por cada seis días de trabajo uno de descanso, como lo previene el presepto indicado. Ese descanso deberá ser las tardes de los Domingos y dlas festivos, eligiendo estas tardes, por que teniendo por objeto el descanso dar expanción ál espíritu y recréo á los sentidos abrumádos por el trabajo consecutivo de seis días, tales días son los únicos, en que en las poblaciones de la categoría de la nuestra, se encuentran medios de honesta distracción, de que se carece en el resto de la semana.

Por tanto, esa Presidencia Municipal atentamente suplicamos se sirva hacer del conocimiento de todos los patrones y dueños de establecimientos mercantiles nuestra petición, y para conciliar sus intereses con

${ }^{11}$ Archivo Municipal de Zamora, Fomento, Expediente 5, 3 fojas, 1919. 
los nuestros, y no provocar un conflicto de derechos, señalar tanto las horas que debe durar la jornada máxima de trabajo, como el día que debemos disfrutar de descanso por cada seis de trabajo, rogando que ese día designádo sea las tardes completas de los Domingos y días festivos.

Esta solicitud del cierre de los establecimientos mercantiles solo comprende á los de ropa, mercería y ferretería.

Recibimos oficios y notificaciónes en el cajón de ropa denominado "El Paje" sito en el Portal Allende de esta Ciudad de Zamora, á 14 de Enero de mil novecientos diecinueve 1919.

Firman: Gonzalo Galván, M. Méndez, Salvador Cuadra, Miguel Villanueva, Carlos Quiroz, Jesús Chávez, Luis Vaca, Joaquín del Rio, Antonio Vaca, Alfonso Vaca, Roberto Vaca.

\section{RESPUESTAPRESISDENTE MUNICIPAL.}

Ciudadanos. Gonzalo Galván, Joaquín del Río y demás signatarios. Presente.

Impuesta esta Presidencia Municipal del contenido del atento ocurso de Uds. fechado ayer, en que solicitan que con motivo de estar encomendado a las autoridades Municipales, hace cumplir las leyes, se ponga en conocimiento de sus patronos la determinación que contiene el artículo 123 de la Constitución General de la República, en sus incisos Iy IV. es decir, que Ud. Solo deban trabajar ocho horas diarias y que por cada seis días de trabajo, se les proporcione uno de asueto.

En debida contestación les manifiesto.

Si bien es cierto que está en el deber de las autoridades municipales velar por el cumplimiento de las leyes, tambien lo es que el artículo 123 constitucional que Uds. invocan, impone a la Legislaturas de los Estados la obligación de expedir leyes reglamentarias sobre el trabajo, lo que no está en las atribuciones Municipales. El Congreso de Michoacán aun no la he verificado, sin embargo de haber recibido del Ejecutivo del Es- 
tado con fecha 7 de Mayo de 1918, un proyecto sobre la expedición de dichaley.

Por otra parte, y en caso de que surgiera algún conflicto de intereses entre Uds. y sus patronos, no son las autoridades municipales las competentes para conocer de estos asuntos, porque la fracción Xx del artículo constitucional citado, confía la resolución de los negocios de esta índole, a las Juntas de Conciliación y Arbitraje, cuyas funciones no puede invadir la autoridad municipal, sin violar la suprema ley de la República.

Lo que se comunica a Uds. para su conocimiento y resultado de su solicitud, protestandoles mis atenciones.

Constitución y Reformas. Zamora, Enero 15 de 1919.

El Presidente Municipal.

\section{RESPUESTADE COMERCIANTES DE ROPA DE ZAMORA.}

CIUDADANO Presidente Municipal. PRESENTE

Los que suscribimos, comerciantes de ropa en esta Ciudad, ante Usted con el devido respeto esponemos; que siendo el Domingo el unico dia de mayor venta para nosotros por ser de constumbre antigua en que en el referido dia vienen de todos los pueblos y Haciendas cercanas á verificar sus compras, nos sentimos perjudicados por este echo en serrar nustros establecimientos el citado dia á las tres de la tarde, hora en que aun podemos verificar la tersera parte de nustras ventas, pues no podemos nosotros ponernos á la altura de las grande Poblaciones ó compararnos con ellas que son las unicas en no abrir sus establesimientos en dia Domingo por ser nustros intereses demasiado pqueños, por otra parte, en dicha poblasiones no solo no se acostumbra, sinno que se prohíbe vender á los ambulantes en la plaza principal, como creemos que aqui no se podra yevar á efecto prohivir á estos que dejen de vender en el citio que mas les acomode, nostros queremos se nos deje también en libertad para vender ese dia asta que cremos innesesario tener avierto nuestros establesimientos. 
Pedimos pues por tal rason trasferir el sierre de los Domingos, por el dia jeves á la una de la tarde para no abrir asta el dia siguiente á las horas de constumbre, con el fin de dar un descanso semanalmente á nustros empleados, pues estos en virtud de no habérseles consedido el sierre del Domingo á la una de la tarde como lo habien solisitado, están conformes en que se trasfiera.

Siendo opositores al sierre de los jueves los Señores Luis Cornejo, Galdino Mares y Rodolfo Paniagua, quedan estos Señores escluidos de este compromiso por ser enteramente agenos á nustro ramo, pudiendo ellos por tal rason, formar ó plantear sus ideas por separado para que no estorben á las nustras.

Creemos por lo que le esponemos, nos conseda nustra peticion y se serbira tomar nota de los puntos siguientes.

$1^{\circ}$ - Que los que firmamos el presente, somos la mayoria.

$2^{\circ}$ - Que los empleados conformes, son también la mayoria.

$3^{\circ}$ - Que siendo inposible salir el Domingo á las tres en punto por no estar desde luego espiditos, venimos á salir una hora después, no asi serrando los Jueves, como á esa hora que es la una de la tarde todos nos vamos á comer, no hay quien buelva asta el siguiente dia.

Por todas estas rasones, pedimos, Presidente, nos conseda nuestra peticion por ser enteramente Justa.

Zamota Febrero 28 de 1919.

Firman: Antonio Herrera S., González S., Moreno, E. Caballero, Jesús Barragán, Heriberto Herrera, Rafael Benítez, M. Villanueva, Ramón Chávez. 